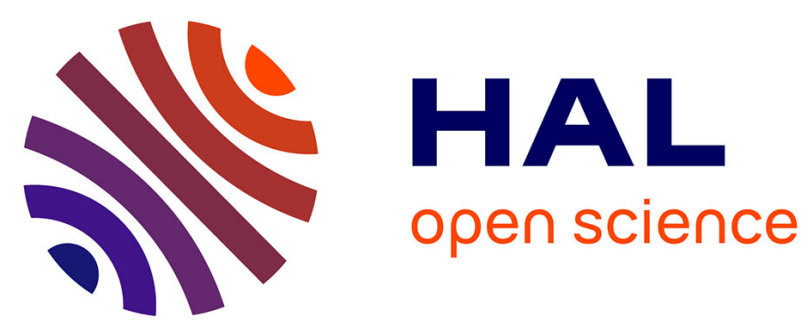

\title{
Experimental analysis of fresh concrete under dynamic loadings
}

\author{
Stéphane Pattofatto, Han Zhao, Arnaud Poitou
}

\section{To cite this version:}

Stéphane Pattofatto, Han Zhao, Arnaud Poitou. Experimental analysis of fresh concrete under dynamic loadings. Journal de Physique IV Proceedings, 2004, 110, pp.447-451. 10.1051/jp4:20020734 . hal-01006830

\section{HAL Id: hal-01006830 \\ https://hal.science/hal-01006830}

Submitted on 17 Feb 2017

HAL is a multi-disciplinary open access archive for the deposit and dissemination of scientific research documents, whether they are published or not. The documents may come from teaching and research institutions in France or abroad, or from public or private research centers.
L'archive ouverte pluridisciplinaire HAL, est destinée au dépôt et à la diffusion de documents scientifiques de niveau recherche, publiés ou non, émanant des établissements d'enseignement et de recherche français ou étrangers, des laboratoires publics ou privés. 


\title{
Experimental analysis of fresh concrete under dynamic loading
}

\author{
S. Pattofatto, H. Zhao and A. Poitou ${ }^{1}$
}

Laboratoire de Mécanique et Technologie, ENS de Cachan, CNRS, UPMC, 61 avenue du Président Wilson, 94235 Cachan cedex, France

${ }^{1}$ Laboratoire de Mécanique et Matériaux, École centrale de Nantes, UPRES EA 2166, BP. 92101, 44321 Nantes cedex 3, France

\begin{abstract}
This paper presents a new experimental technique to study the behavior of fresh concrete submitted to a shock pulse. The aim is to determine the source of the efficiency of dynamical compaction. The test is based on the Hopkinson bars technique. The apparatus is vertical and allows to apply successive impacts on the specimen. Moreover, it allows the indirect measurement of stress and velocity at the interaces between the specimen and the bars. First, measurement technique is validated. Then, the first experimental results are presented : measurement of the velocity of the wave propagating into the material, depending only of the density; and analysis of the efficiency of dynamical compaction compared to quasi-static compaction.
\end{abstract}

\section{INTRODUCTION}

Every work or product in concrete needs a forming phase generally obtained under vibration. It improves workability and mechanical properties of the product. The choice and optimization of the loading path is subjected to the understanding of the mechanisms of compaction. As well as the source of efficiency of dynamics (for vibration or shocks for example). Efficiency being defined here as the density gain for a given load. This study is a contribution to experimental analysis of fresh concrete submitted to a shock pulse. Experimental studies on this type of material can be separated in two kinds. On one hand, specific shearing rheometry has been developped [1]. It resulted in the modelling of sheared fresh concrete as a Herschel-Bulkley material [2]. And on the other hand, the vibration tests $[3,4,5]$ designed to determine vibration parameters governing the efficiency of the process.

In our study, a shock test has been developped. The aim of this experimental analysis is to obtain reliable and quantitative measurements being able to improve the knowledge of fresh concrete behavior under dynamical loads. First the test is presented and analyzed in order to validate the measuring technique. Then results of application upon fresh concrete are given and discussed.

\section{DESCRIPTION OF THE TEST}

\subsection{Material}

The studied material is a fresh concrete, very "dry". It can be described qualitatively like a complex unsaturated granular material. The tested material is a fresh concrete composed of (in \% of dry weight) : granulates $35 \%$, sand $57.3 \%$, cement $7.7 \%$ and water $7.3 \%$. Granular phase is made of crushed slag granulates $(4 / 6 \mathrm{~mm})$ and sand $(0 / 4 \mathrm{~mm})$ in order to follow the granulometric curve. They are not hard and then have good rheological properties: spheroidal shape and friable contacts. All the grains are dried in the atmosphere before mixing with water and cement during two minutes. Thereafter the material is introduced in a "rain" way into the cylindrical vessel. Initial density is baout $1450 \mathrm{~kg} / \mathrm{m}^{3}$ with a good repetability. The vessel characteristics are: diameter $66 \mathrm{~mm}$, height $200 \mathrm{~mm}$ and thichkness $10 \mathrm{~mm}$. Two materials are used for the vessel: aluminum which involves high effects of friction at the wall due to granulates indentation; and steel. The height of the tested material is measured with a ruler between two successive applied shocks. 


\subsection{Experimental device}

Hopkinson bars were introduced by Hopkinson [6] and applied to material testing by Kolsky [7]. Generally used in order to test solid specimen [8], they also served for soils studies [9].

Our device is composed of two cylindrical bars moving vertically (see figure 1) with almost no friction. Fresh concrete is introduced in a vessel fixed to the structure and lies directly in contact with transmitter bar. The test consists in dropping the impact bar onto the specimen to create a shock pulse. Strain measurement of the bars with gauges allow to determine, during the whole shock length, stress and velocity at the interfaces specimen / bars. The material of the bars is chosen in order to have an impedance $Z=\rho C$ (with density $\rho$ and celerity $C$ of the waves) close to the one of the tested material. Fresh concrete has a low cohesion, rejecting the use of metal bars. Polyamid bars are chosen with the following characteristics: diameter $60 \mathrm{~mm}$, density $1042 \mathrm{~kg} / \mathrm{m}^{3}$, wave celerity $\mathrm{C}=1740 \mathrm{~m} / \mathrm{s}$, for a Young modulus of about 3.1 GPa.

Data acquisition is performed by 2 strain gauges on a section of a bar, diametrically opposite and connected to a half-bridge amplifier to compensate the bending; a rapid data acquisition card that digitally samples the signal at $200 \mathrm{kHz}$.

Measurement of the impact velocity is performed by an optic captor.

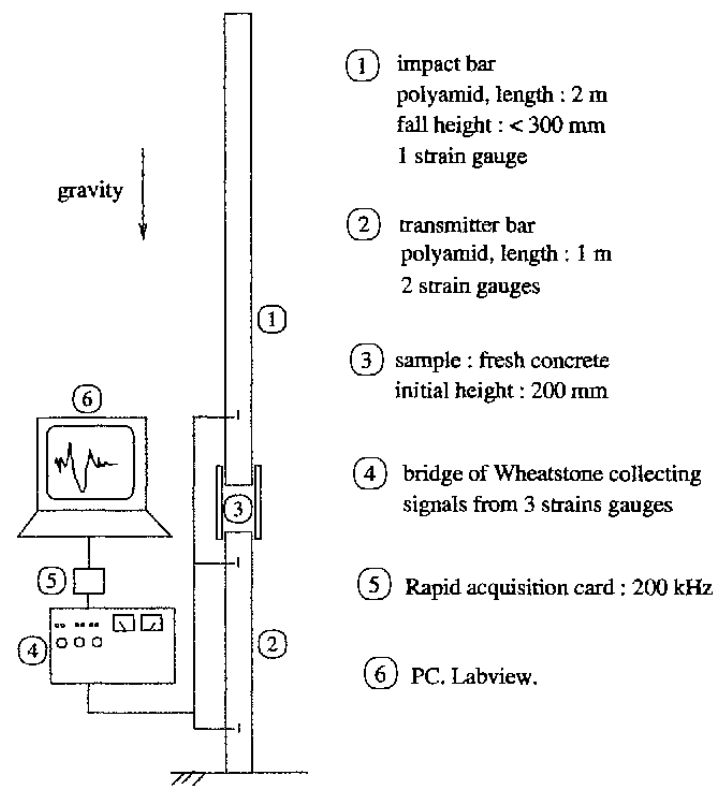

Figure 1 - Experimental device.

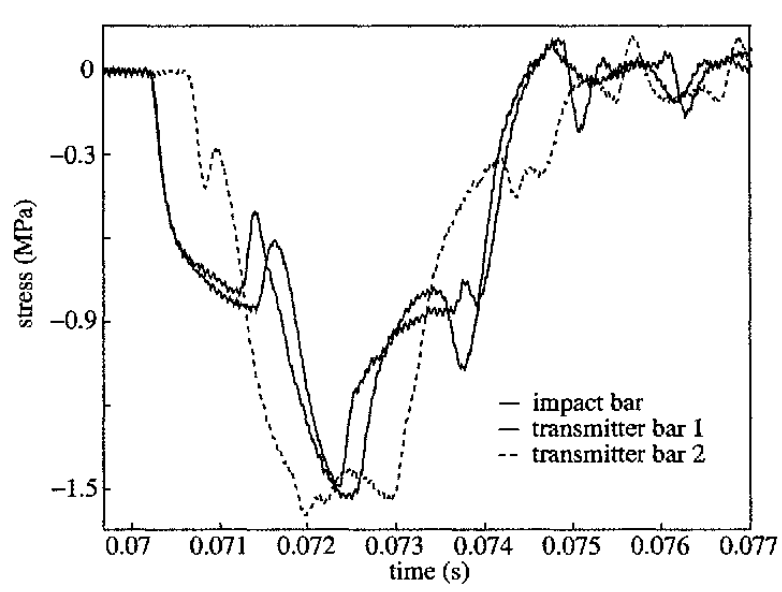

Figure 2 - Raw measurement. Bar against bar test. Drop height $60 \mathrm{~mm}$.

Stress and velocity at the interface is calculated from stress at the measuring points. This indirect measurement technique needs to calculate waves propagating into the bars. This is done under the following assumptions: the propagation is uniaxial and the bars are purely elastic. The algorithm reconstructs the waves from the measures at two different points [10]. For the impact bar, only one section is equipped with strain gauges since it has one free edge. The transmitter bar has to be equipped on two sections because it lies directly on the ground.

\subsection{Validation of the test}

This Hopkinson bars test is not done "classically" : use of polyamide bars, vertical structure and impact velocities of only several meters per second. The validation is then done by a "bar against bar" test.

The figure 2 shows the raw signal measured on the three gauges. On figure 3 is plotted the signal calculated at the interfaces bars / specimen, compared to the signal computed with an explicit finite elements code. The measurement is stated to be good. Moreover, experimental tests proved the repetability. 

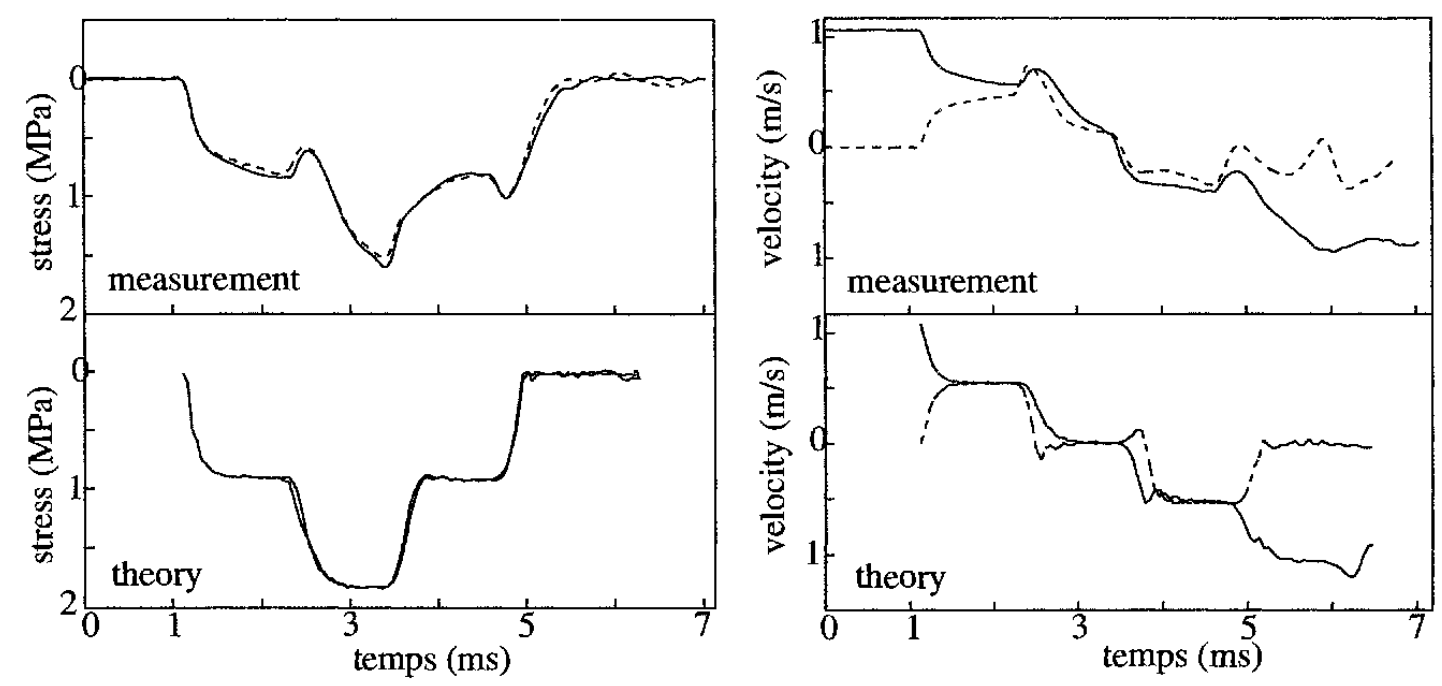

Figure 3 - Reconstructed signal (top) and comparison with theoretical signal (bottom).

\section{EXPERIMENTAL RESULTS}

The very first experimental tests presented are the analysis of the propagation of the wave into the specimen and the dynamical efficiency compared to quasi-static tests. The dynamical tests consist in loading the specimen under successive shocks:

- tests 1,2 and 3: done with the steel vessel; initial height of material: $200 \mathrm{~mm}$, drop height respectively 50,150 and $300 \mathrm{~mm}$,

- tests 4 and 5: done with the lauminum vessel, initial height of material : $200 \mathrm{~mm}$, drop height respectively 50 and $300 \mathrm{~mm}$.

Data acquisitions and meausrements of specimen height are done for every test for shock numbers : 1 to 10 , then $15,20,25,30$, etc. until the compaction gain be almost zero.

Quasi-static tests are performed on a hydraulic machine with the same material and vessels.

\subsection{Delay}

The delay is defined as the time between the stress rise at the interface with the impact bar (corresponding to the impact) and at the interface with the transmitter bar (corresponding to the "arrival" of the wave). Assuming that the impact propagates into the specimen like a uniaxial wave, we can define a constant mean velocity $C_{\rho}$ of the wave going across the specimen. The delay of the first shock is not included in the results because due to the very low cohesion of the material, the measurement is not possible.

The results of the tests done with the steel vessel are showed on figures 4 and 5 . Each point corresponds to a shock. The dashed curve is the mean curve corresponding to test with aluminum vessel.

The velocity depends of the density: increase from 40 to $140 \mathrm{~m} / \mathrm{s}$ for densities varying from 1.8 to 2.2. This velocity increase is almost linear in the range of our study and there is no influence of the drop height nor of the vessel. The effect of the material of the vessel seems to be primarily in the initial density of the specimen, lower in the case of aluminum due to a higher friction at the wall. The order of magnitude of the velocity $C_{\rho}$ is low: about a hundred meters per second. Some tests on the slag granulates only gave the same result.

\subsection{Efficiency of dynamics}

A dynamical curve is extracted from the measurements. The maximal stress during the shock is plotted versus the specimen height after that very shock. One point of the curve for one shock. 


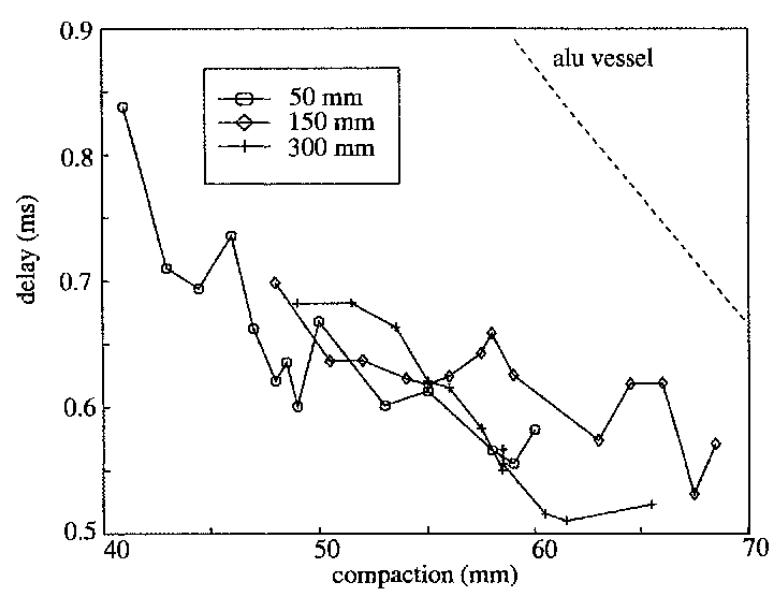

Figure $4-$ Evolution of the delay with compaction (steel vessel).

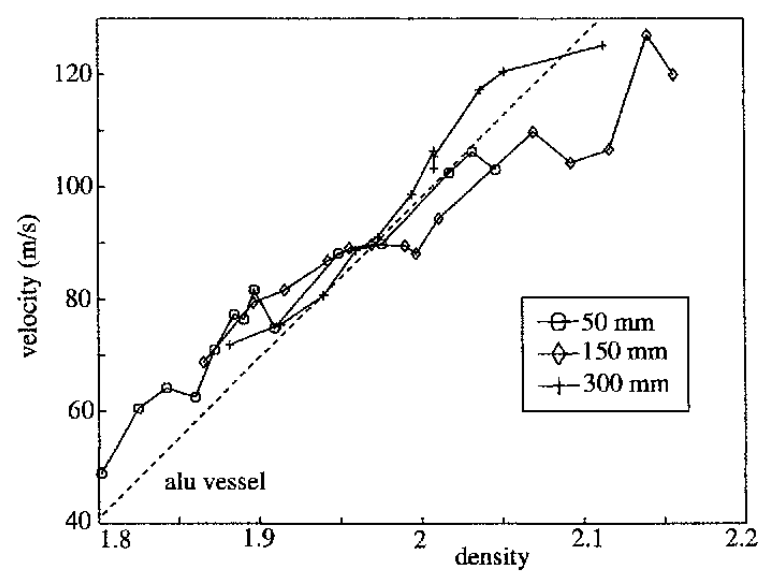

Figure 5 - Evolution of the velocity $C_{\rho}$ with density (steel vessel).

On figure 6 are compared: the mean curve of identical quasi-static tests for each vessel, and dynamical curves of the tests presented before.

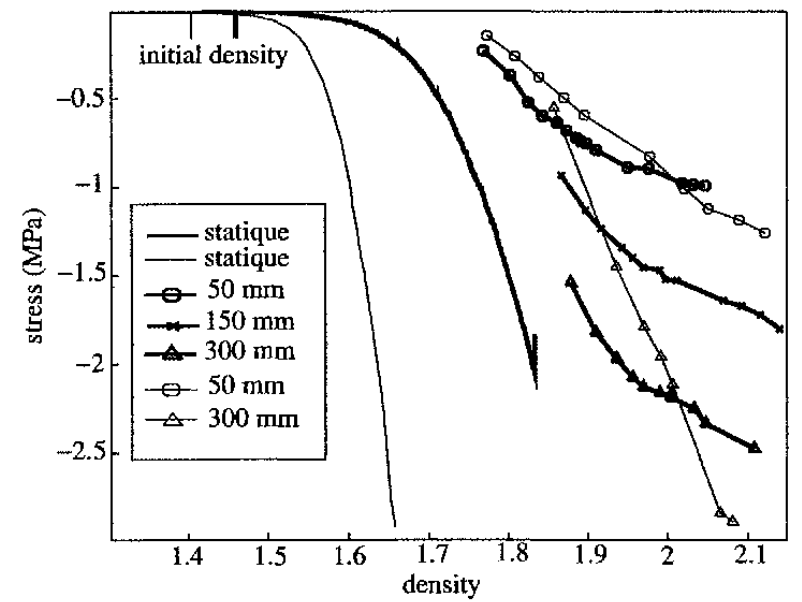

Figure 6 - Quasi-static and dynamical tests. Steel vessel (thick) and aluminum (thin).

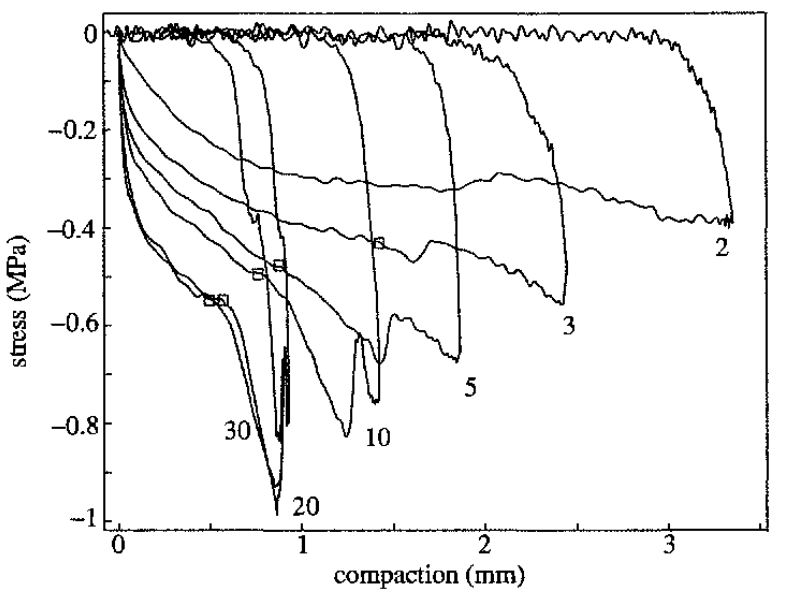

Figure 7 - Evolution of compression curves with compaction (number of the shock). Drop height: $50 \mathrm{~mm}$.

- Dynamical tests are globally more efficient, as early as the first shock.

- Increasing the initial velocity is relatively not efficient because for the same density the stress is more important. However it allows to achieve a more important compaction.

- The influence of the vessel material is visible for a drop height of $300 \mathrm{~mm}$ : an increase of density needs an increase of stress more important in the case of the aluminum vessel.

\subsection{Compression curve}

Measurements given by the bars allow to plot the analogue of "stress/strain" curve for one shock, called compression curve. Meanwhile, given that the stress is not homogeneous into the specimen due to wave propagation, a compression curve is defined as the stress at the interface with impact bar, versus the height of the specimen (difference of the displacements of the two interfaces specimen / bars).

On figure 7 are plotted compression curves of several shocks taken from the test with steel vessel and drop height of $50 \mathrm{~mm}$. As the specimen is getting compacted, the stress increases and the irreversible strain (compaction) decreases. The markers indicate the point of the curve at a time equals 
to double the delay. It's noticeable that the second loading phase is due to a reflection of the wave onto the transmitter bar. For the very first shocks, the reflection is negligible and the second loading phase is rather due to the reflection of the wave onto the ground.

\section{CONCLUSIONS}

In this communication has been presented an original modified Hopkinson bars test apllied to experimental study of fresh concrete. The specimen is loaded under successive impacts of several meters per second. Experimental results about the propagation time of the wave into the specimen are analyzed. They show that it depends only of the density of the concrete. A comparison between quasi-static and dynamical tests proves that a higher compaction is achieved for lower stresses in the case of impacted specimen. The increase of impact velocity is "relatively" not efficient. Further tests are designed to improve the analysis of compression curves in order to analyze the mechianisms of dynamical compaction.

\section{Références}

[1] De Larrard, F., Hu, C., Sedran, T., Szitkar, J.C., Joly, M., Claux, F., Derkx, F., A new rheometer for soft-to-fluid fresh concrete. ACI Mater. J. 94, (1997), 234-243.

[2] De Larrard, F., Ferraris, C.F., Sedran, T., Fresh concrete: A Herschel-Bulkley material. Matériaux et Constructions 31, (1998), 494-498.

[3] Legrand, C., Gourves, R., Etude de l'influence de l'accélération de vibration sur les propriétés rhéologiques des mélanges de sable ou de ciment et d'eau. Essai de définition d'une vibration optimale. C. R. Acad. Sc. Paris, série B t280, (1975), 207-210.

[4] Tattersall, G.H., Baker, P.H., The effect of vibration on the rheological properties of fresh concrete. Mag. Conc. Res. 40, (2000), 809-816.

[5] Petrou, M. F., Harries, K. A., Gadala-Maria, F., Giri-Kolli, V., A unique experimental method for monitoring aggregate settlement in concrete. Cement and Concrete research 30, (1988), 79-89.

[6] Hopkinson, B., A method of measuring the pressure produced in the detonation of high explosives or by the impact of bullets. Philosoph. Trans. Royal Soc. of London 213, (1914), 437-456.

[7] Kolsky, H., An investigation of the mechanical properties of materials at very high rates of loading. Proc. Phys. Soc. 62, (1949), 676-700.

[8] Zhao, H, Analyse de l'essai aux barres de Hopkinson. Application à la mesure du comportement dynamique des matériaux. Thèse de doctorat l'École Nationale des Ponts et Chaussées, (1992).

[9] Semblat, J.F., Luong, M.P., Gary, G., 3D-Hopkinson bar: new experiments for dynamic testing on soils. Soils and Foundations 39, (1999), 1-10.

[10] Zhao, H., Gary, G., A new method for the separation of waves. Application to the SHPB technique for an unlimited duration of measurement. J. Mech. Phys. Solids 45, (1997), 1185-1202. 